\title{
Effects of Splenectomy and Beta-Adrenoceptor Blockade on Cardiac Output Response to Acute Hypoxemia
}

\author{
Chang-seng Liang and William E. Huckabee \\ From the Departments of Medicine and Pharmacology, Boston University \\ School of Medicine and the Departments of Medicine and Clinical Research, \\ University Hospital, Boston, Massachusetts 02118
}

\begin{abstract}
A в S T R ACT Acute hypoxemia produced by the inhalation of $8 \%$ and $5 \%$ oxygen increased cardiac output in intact anesthetized dogs by $38 \%$ and $62 \%$, respectively. Although practolol, a cardioselective betaadrenergic blocking agent, reduced the increase in cardiac output in dogs subjected to severe hypoxemia ( $5 \% \mathrm{O}_{3}$ breathing) from $62 \%$ to $43 \%$, it only slightly reduced the cardiac output rise in dogs subjected to moderate hypoxemia ( $8 \% \mathrm{O}_{2}$ breathing). Splenectomy, on the other hand, abolished the increase in cardiac output produced by moderate hypoxemia except for a small initial rise, but it reduced the increase in cardiac output during severe hypoxemia only to $37 \%$. The entire increase, except for a small initial rise, disappeared only when splenectomized dogs were pretreated with practolol. Sham operation did not affect the cardiac output response to hypoxemia. It is concluded that an intact spleen is required for a significant portion of the increased cardiac output that occurs during both moderate and severe hypoxemia and that catecholamines do not participate in the regulation of cardiac output unless severe hypoxemia occurs.
\end{abstract}

\section{INTRODUCTION}

In the preceding paper (1), we have shown that the spleen and beta-adrenergic receptors are responsible for the major part of the cardiac output rise that occurs in dogs after intra-aortic infusion of cyanide. Cyanide produces metabolic changes like those that occur in hypoxic tissues. The present study was designed to ascertain whether the spleen and beta-adrenergic receptors are similarly important in the control of cardiac

Dr. Liang was the recipient of a National Institutes of Health Special Research Fellowship (1 F3 HL 52986).

Received for publication 12 March 1973 and in revised form 16 July 1973. output when hypoxia is produced by the inhalation of low-oxygen gas mixtures.

\section{METHODS}

Dogs weighing from 15.5 to $30 \mathrm{~kg}$ were anesthetized and prepared as described in the preceding paper (1). The tracheal cannula was connected to a Douglas bag via a "J" valve system for determining oxygen consumption. The volume of expired gas was measured in a Tissot spirometer and the gas contents were analyzed by gas chromatography (2). Arterial blood $\mathrm{pH}, \mathrm{PO}_{2}$ and $\mathrm{PCO}_{2}$ were measured on a Radiometer PHM 71 acid-base analyzer (The London Company, Westlake, Ohio). Cardiac output, systemic arterial and right ventricular pressures, heart rate, and arterial blood lactate and pyruvate concentrations were determined as described previously (1).

Control measurements of these metameters in dogs breathing room air were obtained in duplicate or triplicate over a 20 -min period. Acute hypoxemia was produced by switching breathing from room air to either an $8 \%$ or a $5 \%$ oxygen-in-nitrogen mixture for $10 \mathrm{~min}$. Blood pressures and heart rate were monitored continuously throughout the period of hypoxemia. Cardiac output was determined every 2 or $3 \mathrm{~min}$ by the dye-dilution technique; results are shown in Figs. 1 and 2. Fick cardiac outputs obtained between 5 and $8 \mathrm{~min}$ after the beginning of low oxygen gas breathing were used for statistical analyses shown in Tables I and II. Arterial blood $\mathrm{pH}$ and gas tensions were measured at the time of Fick cardiac output determination. The average of two determinations of lactate and pyruvate concentrations sampled at 5 and $10 \mathrm{~min}$ after the onset of hypoxemia in each experiment was used in the statistical summary reported in Results.

Each dog was subjected to a hypoxic mixture only once. Intact and sham-operated dogs were studied as controls before and after the administration of either 8 or $5 \%$ oxygen-nitrogen mixture. Acute hypoxemia was also produced in splenectomized dogs and in dogs pretreated intravenously with $3 \mathrm{mg} / \mathrm{kg}$ of practolol, ${ }^{1}$ a cardioselective betaadrenoceptor blocking agent (3). Another group studied was one of splenectomized dogs pretreated with the same dose of practolol and subjected to $5 \%$ oxygen-nitrogen mix-

\footnotetext{
${ }^{1}$ Kindly supplied by Ayerst Laboratories, Div. of Ameri-
} can Home Products Corp., New York. 
ture. Experiments were begun $30 \mathrm{~min}$ after practolol administration. The effects of practolol were measured by comparing the heart rate and dye cardiac output responses to isoproterenol $(0.5 \mu \mathrm{g} / \mathrm{kg})$ given intravenously immediately before and $1 \mathrm{~h}$ after administration of practolol. Experimental results were analyzed with the $t$ test for paired comparison, analysis of variance, and Kramer's multiple range test (4).

\section{RESULTS}

Results are summarized in Tables I and II. Except for the relatively low cardiac output in practolol-pretreated splenectomized dogs, all metameters obtained before induction of hypoxemia were comparable among groups, as determined by analysis of variance. The differences among groups in response to hypoxemia were deter- mined by comparing their changes from prehypoxemic values with Kramer's multiple range test.

A significant degree of cardiac beta-adrenoceptor blockade was produced by practolol. The increase in cardiac output induced by isoproterenol was reduced by practolol from $69.0 \pm 7.5 \%$ (mean \pm SEM) of the control to $18.2 \pm 3.6 \%$, and the increase in heart rate, from $71.5 \pm 9.5$ beats $/ \mathrm{min}$ to $12.7 \pm 2.8$ beats $/ \mathrm{min}(P<$ 0.001 in both instances).

Effects of $8 \%$ oxygen gas breathing. Intact, shamoperated, practolol-pretreated, and splenectomized dogs were studied. The dogs in all four groups showed a uniform decrease in arterial $\mathrm{Po}_{2}$ to values averaging $32 \mathrm{~mm} \mathrm{Hg}$ when subjected to $8 \%$ oxygen-nitrogen mixture, a decrease in arterial $\mathrm{PCO}_{2}$ and an increase

TABLE I

Effects of $8 \%$ Oxygen Breathing in Four Groups of Dogs ( $n=8$ in Each Group)

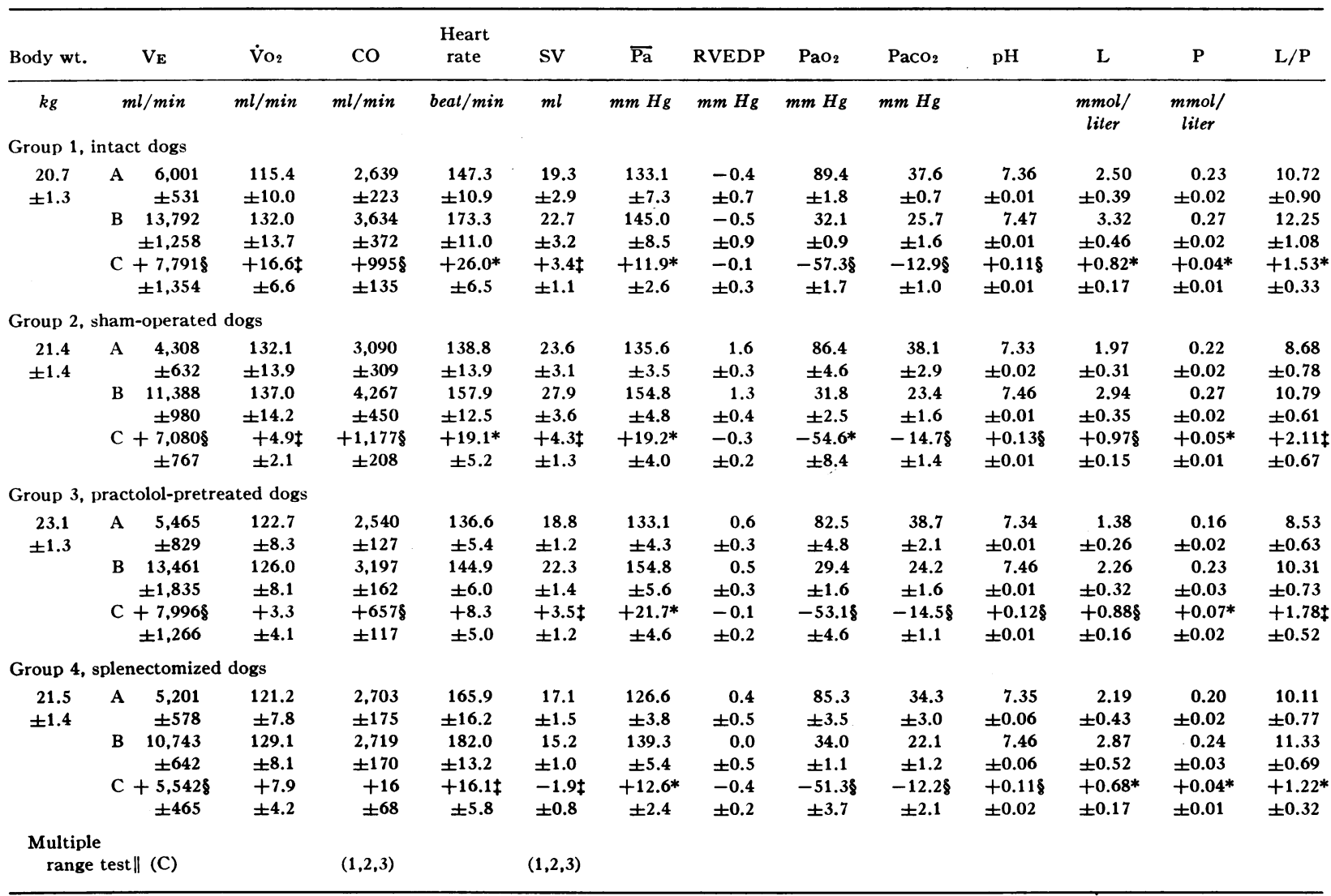

Abbreviations and symbols are as follows: A, prehypoxemic controls; B, values obtained during hypoxemia, C, differences between hypoxemia and contro (B - A) ; CO, cardiac output; L, lactate concentration in arterial blood water; $P$, pyruvate concentration in arterial blood water; $R$ VEDP, right ventricular end-diastolic pressure; SV, stroke volume; $\dot{V}_{E}$, minute ventilation; $\dot{V}_{2}$, oxygen consumption. Values are mean $\pm S E M$.

$* P<0.01$ for difference from zero.

$\ddagger P<0.05$ for difference from zero.

$P<0.001$ for difference from zero.

$\|$ The means of any two groups not appearing together within the same parentheses are significantly different at $P<0.05$. The means of any two groups appearing together within the same parentheses are not significantly different. No parentheses are given when all groups did not differ significantly $(P>0.05)$ 
in arterial $\mathrm{pH}$. Blood lactate and pyruvate concentrations and lactate to pyruvate $(\mathrm{L} / \mathrm{P})^{2}$ ratio increased slightly but significantly. Among the four groups, there was no significant difference in any of these metameters (Table I).

Fig. 1 shows that in intact dogs cardiac output increased with induction of hypoxemia, reaching a maximum of $38 \%$ of the prehypoxemic value in 5 min with no changes during the second $5 \mathrm{~min}$ of hypoxemia. This increase in cardiac output was not affected significantly by sham operation.

Pretreatment with practolol did not prevent the cardiac output from rising during hypoxemia. Cardiac output was increased maximally $5 \mathrm{~min}$ after the onset of hypoxemia, declining slightly thereafter but to no significant extent. When compared with intact and shamoperated dogs, practolol-pretreated dogs showed a smaller average increase in cardiac output during hypoxemia, but the differences were not statistically significant (Table I). In contrast, removal of the spleen markedly reduced the increase in cardiac output that occurred during hypoxemia. In splenectomized dogs, acute hypoxemia resulted in only a slight increase in cardiac output ( $+9 \%$ of the prehypoxemic value) in the first few minutes. Cardiac output was not increased during the last $5 \mathrm{~min}$ of hypoxemia (Table I, Fig. 1).

Hyperventilation occurred in all animals during hypoxemia. On the average, respiratory rate increased by $10.1 \mathrm{cycle} / \mathrm{min}$, and minute ventilation by $132 \%$ of the control (Table I). Table I also shows that oxygen consumption remained unchanged or increased slightly during hypoxemia. Heart rate increased significantly during hypoxemia in intact, sham-operated, and splenectomized dogs, but not in dogs pretreated with practolol. Stroke volume increased in all groups except that of splenectomized dogs, in which the stroke volume decreased. Furthermore, mean arterial blood pressure $(\overline{\mathrm{Pa}})$ and right ventricular end-diastolic pressure remained unchanged in all groups during hypoxemia. No significant difference was found among groups except with respect to changes in stroke volume (Table I).

Effects of $5 \%$ oxygen gas breathing. Five groups of dogs were studied (see Table II). Arterial $\mathrm{Po}_{2}$ decreased markedly during hypoxemia to values averaging $23 \mathrm{~mm} \mathrm{Hg}$; arterial $\mathrm{PCO}_{2}$ fell and $\mathrm{pH}$ increased. Blood concentrations of lactate and pyruvate increased and the $\mathrm{L} / \mathrm{P}$ ratio rose. Again, there was no significant difference in any of these metameters among the five groups of dogs.

Fig. 2 shows that during hypoxemia, cardiac output increased steadily, with a maximum increase averaging $62 \%$ above the prehypoxemic value in $5 \mathrm{~min}$ in both

'Abbreviation used in this paper: $\mathrm{L} / \mathrm{P}$, lactate to pyruvate.

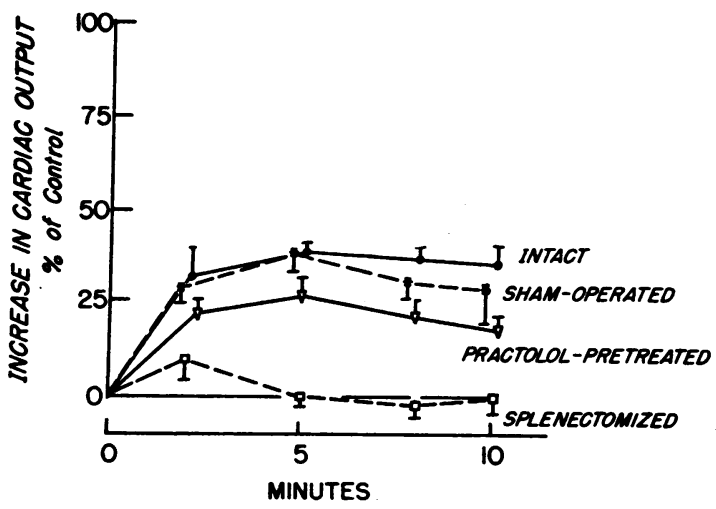

FIGURE 1 Changes in cardiac output in four groups of dogs breathing $8 \% \mathrm{O}_{2}-\mathrm{N}$, gas mixture. Means and $\mathrm{SE}$ are shown.

intact and sham-operated dogs, whereas it increased to an average of only $43 \%$ and $37 \%$ in splenectomized and practolol-pretreated dogs, respectively. In practololpretreated splenectomized dogs, cardiac output returned toward the prehypoxemic level in $5 \mathrm{~min}$ after a small initial rise during hypoxemia. The small increase in cardiac output observed during the last half of the hypoxemic period was not statistically significant.

All animals hyperventilated during $5 \%$ oxygen gas breathing with an average increase in respiratory rate of $16.5 \mathrm{cycle} / \mathrm{min}$. Table II shows minute ventilation increased by an average of $248 \%$ of the control. Oxygen consumption remained either unchanged or diminished slightly. Heart rate increased markedly in intact, sham-operated, and splenectomized dogs, but not in the two groups of dogs pretreated with practolol. Stroke volume increased in intact and practolol-pretreated dogs but no significant changes were found in the other three groups. $\overline{\mathrm{Pa}}$ increased significantly in all animals except the practolol-pretreated splenectomized dogs. Finally, right ventricular end-diastolic pressure did not change significantly during hypoxemia in any of the groups studied.

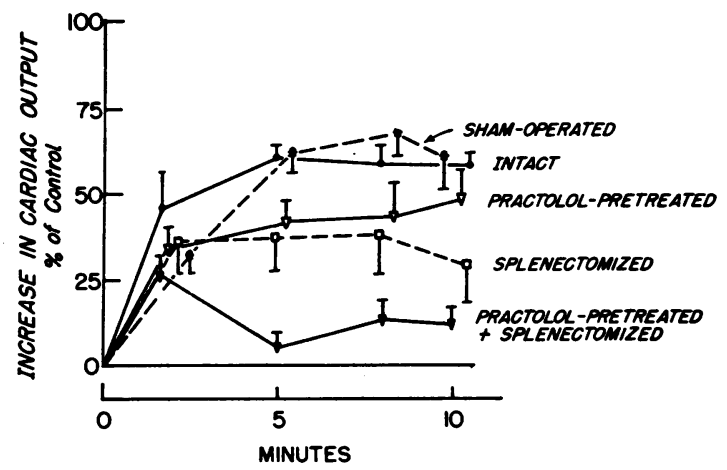

FIgURE 2 Changes in cardiac output in five groups of dogs breathing $5 \% \mathrm{O}_{2}-\mathrm{N}_{2}$ gas mixture. Means and $\mathrm{SE}$ are shown. 
TABLE II

Effects of 5\% Oxygen Breathing in Five Groups of Dogs ( $n=5$ in Each Group)

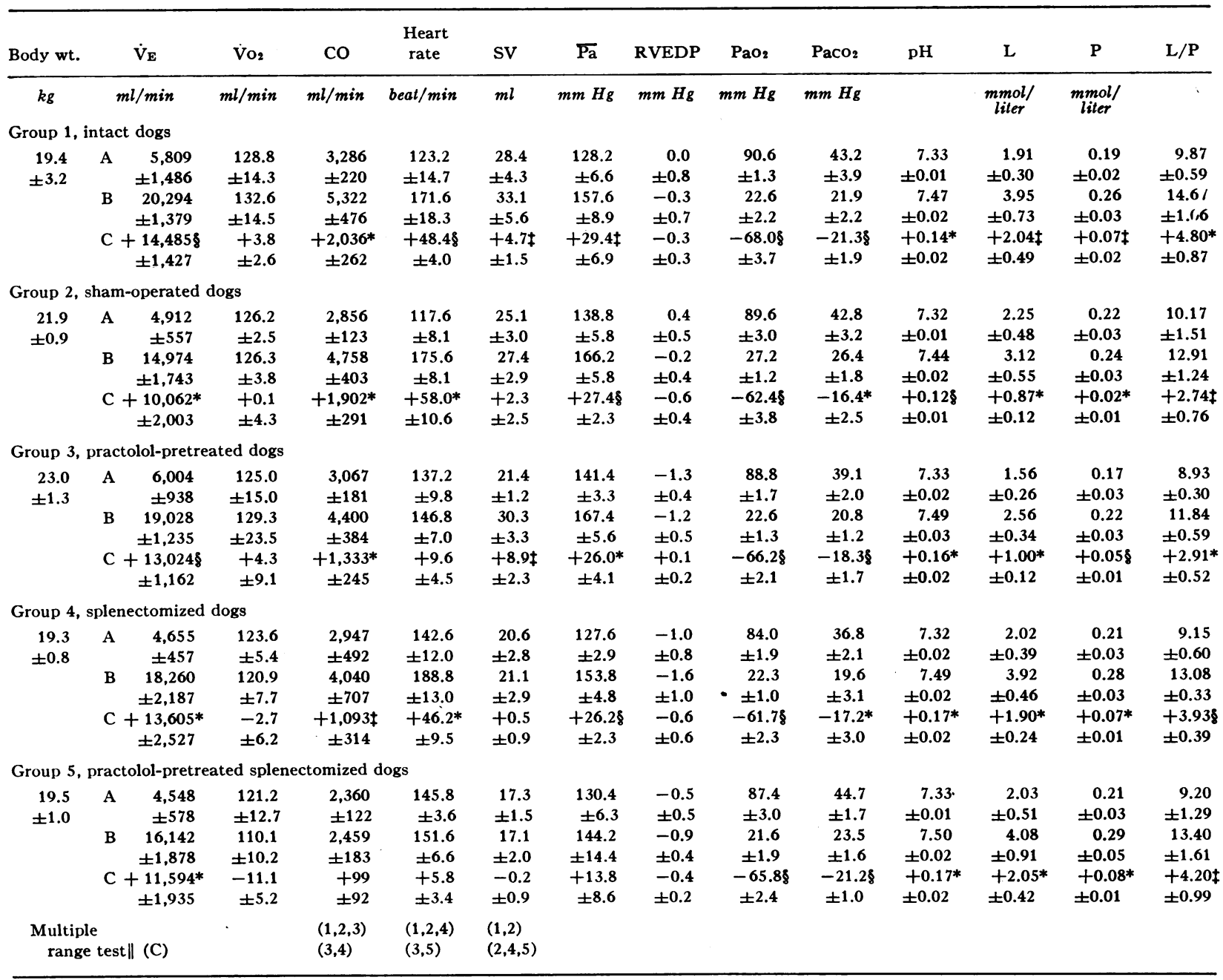

Abbreviations and symbols are as follows: A, prehypoxemic controls; $\mathrm{B}$, values obtained during hypoxemia, $\mathrm{C}$, differences between hypoxemia and control (B - A) ; CO, cardiac output; L, lactate concentration in arterial blood water; P, pyruvate concentration in arterial blood water; RVEDP, right ventricular end-diastolic pressure; SV, stroke volume; $\dot{V}_{E}$, minute ventilation; $\dot{V}_{2}$, oxygen consumption. Values are mean \pm SEM.

$* P<0.01$ for difference from zero.

$\ddagger P<0.05$ for difference from zero.

$P<0.001$ for difference from zero.

$\|$ The means of any two groups not appearing together within the same parentheses are significantly different at $P<0.05$. The means of any two groups appearing together within the same parentheses are not significantly different. No parentheses are given when all groups did not differ significantly $(P>0.05)$.

\section{DISCUSSION}

No generally accepted mechanisms satisfactorily explain the cardiac output response to respiratory hypoxemia (5). Bücherl and Rein (6) found that splenectomy reduced the pressor response to respiratory hypoxemia, but cardiac output measurements were not made. The roles of catecholamines and beta-adrenergic receptors in the regulation of cardiac output during hypoxemia have been studied with conflicting results.
Harrison, Blalock, Pilcher, and Wilson (7) found adrenalectomy did not prevent the cardiac output from rising during hypoxemia. Richardson, Kontos, Raper, and Patterson (8) reported that this increase in cardiac output was reduced but not abolished by betaadrenergic blocking agents. On the other hand, Nahas, Mather, Wargo, and Adams (9) and Baugh, Cornett, and Hatcher (10) found that the cardiac output rise was abolished by adrenalectomy. The reason for the differences in results is not known. 
The period of hypoxic breathing was limited to 10 min in the present experiments to avoid the cardiac depression that usually occurs in dogs subjected to a longer period of anoxia $(11,12)$. Figs. 1 and 2 show that a 10 -min period was sufficient for dogs to achieve a stabilized maximum increase in cardiac output. The marked decrease in arterial $\mathrm{Po}_{2}$ and increases in lactate concentration and $\mathrm{L} / \mathrm{P}$ ratio indicated that tissue hypoxia had occurred in all experimental animals. Blood $\mathrm{L} / \mathrm{P}$ ratios changed inversely with arterial $\mathrm{Po}_{2}$ (Tables I and II).

The experimental results show that cardiac output increased in intact dogs during acute hypoxemia and that this rise was significantly related to the fall in arterial $\mathrm{Po}_{2}$ (Tables I and II). The cardiac output response was not altered to any significant extent by sham operation. The changes in cardiac output and other cardiovascular responses are comparable to those reported by other investigators $(10,13-15)$.

The importance of the spleen and of beta-adrenergic receptors in the regulation of cardiac output during hypoxemia was demonstrated in the experiments with splenectomized and practolol-pretreated dogs. Splenectomy abolished the stabilized maximum increase in cardiac output during moderate hypoxemia ( $8 \%$ oxygen breathing), leaving a small initial rise. During severe hypoxemia (5\% oxygen breathing) the maximum rise was reduced by splenectomy; the residual increase was further reduced by beta-adrenoceptor blockade. We have demonstrated in the preceding paper that the spleen contributes to the regulation of the cardiac output by releasing an inotropic humoral substance under sympathetic influence. We have also shown that direct sympathetic stimulation of the spleen increases cardiac output (16). A similar mechanism may account for the effect of splenectomy on the cardiac output response to hypoxemia. It is then expected that this effect of splenectomy can be reproduced by sympathectomy. In accord with the present experiments, Korner and White (17) found that the normal increase in cardiac output was abolished in rabbits that were adrenalectomized and chemically sympathectomized with guanethidine.

Since the increased cardiac output during moderate hypoxemia was abolished by splenectomy and was not significantly altered by pretreatment with practolol, it seems likely that catecholamines do not play an important role in moderate hypoxemia. The results are consistent with the observation that plasma epinephrine levels do not increase during hypoxemia until severe hypoxemia occurs $(8,18,19)$.

A small early increase in cardiac output during hypoxemia is not attributable to actions of the spleen and catecholamines (Figs. 1 and 2). Penna, Soma, and
Aviado (20) found that this early increase in cardiac output was affected neither by arterial chemoreceptor denervation nor by complete spinal anesthesia. They attributed the increased cardiac output, in part at least, to increased venous return. This speculation, however, was not confirmed by the present study because right ventricular end-diastolic pressure did not increase (Tables I and II).

Acute hypoxemia produced hypocapnic hyperventilation in all dogs in the present study (Tables I and II). Recently, Richardson, Kontos, Raper, and Patterson (21) found that hypocapnic hyperventilation produced a transient increase in cardiac output that disappeared after $4 \mathrm{~min}$. The investigators concluded that the cardiac output response depends mainly on the production of hypocapnic alkalosis, because isocapnic hyperventilation had no effect on cardiac output. Pretreatment with propranolol did not alter the increase in cardiac output produced by hypocapnic hyperventilation. Furthermore, Kontos, Mauck, Richardson, and Patterson (22) found that when hyperventilation was prevented with artificial respiration, cardiac output did not increase during the first $5 \mathrm{~min}$ of hypoxemia. It is possible, then, that the small initial increase in cardiac output observed in our experiments was caused by the hypocapnic alkalosis, invariably associated with the production of respiratory hypoxemia.

In conclusion, the increase in cardiac output produced by hypoxemia can be ascribed to three different components, as in the cyanide model of hypoxia (1). The first component, expressed by the small initial rise, is affected by neither splenectomy nor beta-adrenergic receptor blockade. The second component, necessary in order to achieve a maximal cardiac output increase during both moderate and severe hypoxemia, appears to be mediated by a humoral agent released from the spleen. The third component, attributed to the inotropic action of catecholamines, does not play an important role until severe hypoxemia occurs.

The present study shows that several mechanisms control the change in cardiac output that occurs during hypoxemia. Moreover, the contributions of the several mechanisms to the total increase in cardiac output vary with the severity and duration of hypoxemia. Such contradictory results as have been reported in the literature may be attributable to dissimilar experimental conditions of hypoxemia employed in these studies.

\section{ACKNOWLEDGMENTS}

The authors thank Adele Rymut, Joan Luthy, Song Que Lee, Janet Snader, and Dan Derber for their technical assistance. We also thank Drs. William B. Hood, Jr. and $\mathrm{J}$. Worth Estes for invaluable criticism in the preparation of this manuscript. 
This work was supported by Public Health Service Research Grant HL-06297 and Program Project Grant HE-07299.

\section{REFERENCES}

1. Liang, C., and W. E. Huckabee. 1973. Mechanisms regulating the cardiac output response to cyanide infusion, a model of hypoxia. J. Clin. Invest. 52: 3115.

2. Ramsey, L. H. 1959. Analysis of gas in biological fluids by gas chromatography. Science (Wash. D. C.). 129: 900 .

3. Dunlop, D., and R. G. Shanks. 1968. Selective blockade of adrenoceptive beta receptors in the heart. $B r . J$. Pharmacol. Chemother. 32: 201.

4. Kramer, C. Y. 1956. Extension of multiple range tests to group means with unequal numbers of replications. Biometrics. 12: 307

5. Korner, P. I. 1959. Circulatory adaptations in hypoxia. Physiol. Rev. 39 : 687.

6. Bücherl, E., and H. Rein. 1949. Uber ein Regulationssystem "Milz-Leber" für den oxydativen Stoffwechsel der Körpergewebe und besonders des Herzens. Part II. Naturwissenschaften. 36: 260.

7. Harrison, T. R., A. Blalock, C. Pilcher, and C. P. Wilson. 1927. The regulation of circulation. VIII. The relative importance of nervous, endocrine and vascular regulation in the response of the cardiac output to anoxemia. Am. J. Physiol. 83: 284.

8. Richardson, D. W., H. A. Kontos, A. J. Raper, and J. L. Patterson, Jr. 1967. Modification by beta-adrenergic blockade of the circulatory responses to acute hypoxia in man. J. Clin. Invest. 46: 77.

9. Nahas, G. G., G. W. Mather, J. D. M. Wargo, and W. L. Adams. 1954. Influence of acute hypoxia on sympathectomized and adrenalectomized dogs. Am. J. Physiol. $177: 13$.

10. Baugh, C. W., R. W. Cornett, and J. D. Hatcher. 1959. The adrenal gland and the cardiovascular changes in acute anoxic anoxia in dogs. Circ. Res. 7: 513.
11. Sands, J., and A. C. DeGraff. 1925. The effects of progressive anoxemia on the heart and circulation. $\mathrm{Am}$. J. Physiol. 74 : 416.

12. Wiggers, C. J. 1941. Cardiac adaptations in acute progressive anoxia. Ann. Intern. Med. 14: 1237.

13. Gorlin, R., and B. M. Lewis. 1954. Circulatory adjustments to hypoxia in dogs. J. Appl. Physiol. 7: 180.

14. Nahas, G. G., M. B. Visscher, G. W. Mather, F. J. Haddy, and H. R. Warner. 1953. Influence of hypoxia on the pulmonary circulation of nonnarcotized dogs. $J$. Appl. Physiol. 6: 467.

15. Smith, E. E., and J. W. Crowell. 1967. Influence of hypoxia on mean circulatory pressure and cardiac output. Am. J. Physiol. 212: 1067.

16. Liang, C., and W. E. Huckabee. 1973. Effects of sympathetic stimulation of the spleen on cardiac output. Am. J. Physiol. 224: 1099.

17. Korner, P. I., and S. W. White. 1966. Circulatory control in hypoxia by the sympathetic nerves and adrenal medulla. J. Physiol. (Lond.). 184: 272.

18. Ludemann, H. H., M. G. Filbert, and M. Cornblath. 1955. Application of a fluorometric method for adrenaline-like substances in peripheral plasma. J. Appl. Physiol. $8: 59$.

19. Toyooka, E. T., and W. D. Blake. 1961. Effect of hypoxia on sympathoadrenal activity in dogs with myocardial insufficiency. Am. J. Physiol. 201: 448

20. Penna, M., L. Soma, and D. M. Aviado. 1962. Role of carotid and aortic bodies in mediating the increase in cardiac output during anoxemia. Am. J. Physiol. 203: 133.

21. Richardson, D. W., H. A. Kontos, A. J. Raper, and J. L. Patterson, Jr. 1972. Systemic circulatory responses to hypocapnia in man. Am. J. Physiol. 223: 1308.

22. Kontos, H. A., H. P. Mauck, Jr., D. W. Richardson, and J. L. Patterson, Jr. 1965. Mechanism of circulatory responses to systemic hypoxia in the anesthetized dog. Am. J. Physiol. 209 : 397. 